\title{
Assessment of COVID-19 Cases by Haematological and Biochemical Markers: A Tertiary Care Hospital Study in Dhaka, Bangladesh
}

\author{
Sanjoy Kumar Saha ${ }^{1, *}$, Md. Nuruzzaman², Sajalendu Biswas ${ }^{3}$, Amitav Saha ${ }^{4}$, \\ Mohammad Obayedur Rahman ${ }^{5}$, Mohammad Asaduzzaman ${ }^{6}$ \\ ${ }^{1}$ Department of Medicine, Bashundhara Ad-Din Medical College Hospital, Dhaka, Bangladesh \\ ${ }^{2}$ Department of Medical Gastroenterology, Sheikh Russell National Gastroliver Institute \& Hospital, Dhaka, Bangladesh \\ ${ }^{3}$ Department of Gastroenterology, Shaheed Suharawardy Medical College Hospital, Dhaka, Bangladesh \\ ${ }^{4}$ Department of Gastroenterology, Dhaka Medical College and Hospital, Dhaka, Bangladesh \\ ${ }^{5}$ Department of Gastroenterology, Sheikh Russell National Gastroliver Institute \& Hospital, Dhaka, Bangladesh \\ ${ }^{6}$ Department of Hepatology, Mugda Medical College and Hospital, Dhaka, Bangladesh \\ Email address: \\ sahasanjoy072@gmail.com (S. K. Saha) \\ ${ }^{*}$ Corresponding author
}

\section{To cite this article:}

Sanjoy Kumar Saha, Md. Nuruzzaman, Sajalendu Biswas, Amitav Saha, Mohammad Obayedur Rahman, Mohammad Asaduzzaman. Assessment of COVID-19 Cases by Haematological and Biochemical Markers: A Tertiary Care Hospital Study in Dhaka, Bangladesh. European Journal of Preventive Medicine. Vol. 9, No. 5, 2021, pp. 133-139. doi: 10.11648/j.ejpm.20210905.14

Received: September 13, 2021; Accepted: October 12, 2021; Published: October 29, 2021

\begin{abstract}
Background: On 8 March 2020 the first COVID-19 case was detected in Bangladesh. Day by day this disease is changing its own nature and dimension. So, it is very difficult to define the exact risk factors associated with such ferocious diseases. In this situation, haematological and biochemical analysis of COVID-19 patients may play an important role in the current and future planning of COVID treatment. Aim of the study: The aim of this study was to assess the COVID-19 status of Covid patients by haematological and biochemical markers. Materials and Methods: This prospective observational study was conducted among 350 participants who attended the Bashundhara Ad-Din Medical College Hospital, Hasnabad, South Keranigonj, Dhaka, Bangladesh after confirmation by RT-PCR. Using $5 \mathrm{ml}$ fasting venous blood samples different haematological and biochemical biomarkers were analyzed. These were analyzed in auto analysis using a standard protocol as per the manufacturer's instructions. Finally, results were analyzed using standard statistical calculation by\% positivity, confidence interval, $p$ values where $p \leq 0.05$ was considered as statistically significant. Results: In this study, in critical participant group, the mean $( \pm \mathrm{SD}) \mathrm{HBC}, \mathrm{RBC}, \mathrm{TLC}, \mathrm{PCV}$, NLR, Platelet Counts, SGOT and SGPT were found $11.56 \pm 2.07,3.64 \pm 2.82,12372 \pm 2920$, $29.17 \pm 7.84,2.8 \pm 0.32,98743 \pm 32127,67.91 \pm 31.54$ and $71.39 \pm 33.74$ respectively. On the other hand, in non-critical patient group those reading were found $12.78 \pm 2.17,4.02 \pm 2.90,10956 \pm 2744,35.03 \pm 8.22,2.7 \pm 0.28,129544 \pm 51228,65.68 \pm 27.96$ and $67.55 \pm 26.57$ respectively. In analyzing the haematological and biochemical parameters among participants we found 'extremely significant correlations' between critical and non-critical groups in HBC, TLC, PCV, Platelet Counts, S. Creatinine and D-Dimer test results where $\mathrm{p}$ values were $<0.0001$. On the other hand, we found only 'significant correlation' between critical and noncritical groups in NLR, CRP, Serum Ferritin and LDH test results where the $p$ values were $<0.05$. The average age of the total participants was $47.27 \pm 14.66$ years. In the critical group, it was $54.19 \pm 15.23$ and in the non-critical group, it was $43.03 \pm 13.68$ years. So, the mean age of critical patients was higher than that of non-critical patients. Conclusion: Haematological and biochemical markers may be considered as the most potential parameters in assessing the severity of COVID-19 infection. But, advanced training required for laboratory personnel's who are responsible for collecting, transporting and handling biological samples and carrying out the various laboratory tests for patients with COVID-19 is recommended.
\end{abstract}

Keywords: COVID-19, SARS-CoV-2, Haematological, Biochemical Markers, Bangladesh 


\section{Introduction}

It is very difficult to define the exact risk factors and pathological status associated with COVID-19. In this situation, haematological and biochemical analysis of COVID-19 patients may play an important role in the current and future planning of COVID treatment. At the end of the year 2019, a single cluster of pneumonia cases produced by a novel coronavirus (2019-novel) was reported in Wuhan of China. [1] In Later, the term 'severe acute respiratory syndrome corona virus-2' or SARS-CoV-2 was coined. Because of the contagious nature of it can spread rapidly. For its rapid progression and due to lack of specific predefined paretic strategy, an epidemic had occurred. [1] In Bangladesh, on 8 March 2020 the first COVID-19 case was detected. World Health Organization (WHO) declared that the epidemic of SARS-CoV-2 is a public health emergency of international concern (PHEIC) on 30 January 2020. As per the phylogenetic analysis, 'COVID-19' belongs to a distinct clade of 'beta-corona virus' which is similar to the 'human SARS-CoV-1' and 'Middle East Respiratory Syndrome Coronavirus (MERS-CoV) and these two species found in the latest decade causing severe human deaths. [2] Although the estimated case fatality rate (CFR) of COVID-19 is lower than that of 'SARS or MERS', the scale of its contagion has caused more casualties than either of them. [3] Within a few days, human-to-human transmission of COVID-19 has been confirmed. [4] The SARS-CoV-2 can be because of some serious clinical complications, especially in elderly patients, cases with diabetes, [5] cardiac and cerebrovascular diseases, [6] cancer, obesity, patients of endocrine, nerves, and respiratory systems. [7] Basically, such patients constituting $50 \%-75 \%$ of deaths, [8] pertaining to COVID-19 infections. The RT-PCR is the standard method for SARS-CoV-2 detection and it is the laboratory test of choice for the diagnosis of symptomatic patients in the acute phase. [9] Besides this, biomarkers offer information concerning the nature and degree of pneumonia. A physician can determine whether a disease is bacterial or resultant any other etiology by analyzing blood test results. [10] The findings regarding elevated serum C-reactive protein (CRP), LDH, D-dimer, and hyper-ferritin status in blood suggest a possibly crucial role of a cytokine storm in the pathophysiology of COVID-19 infection. [11] The main biomarker molecules that are being evaluated are; D-dimer, CRP, LDH, and serum ferritin. The elevated levels of these biomarkers were associated with severity of inflammation and bleeding associated with COVID-19 infection, showing an independent increased risk for admission in the Intensive Care Unit (ICU), invasive ventilatory support, and death. The highest odds of death occurred when levels of the serum LDH level were greater than 1200 units per liter, and the D-dimer level was greater than $3 \mu \mathrm{g} / \mathrm{ml}$. Additionally increased level of ALT, AST, and creatinine level in severely infected patients suggests; that SARS-CoV-2 carries an increased risk of impaired/deranged liver and kidney function [12]. The main objective of this study was to assess the COVID-19 status of Covid patients by haematological and biochemical markers.

\section{Materials and Methods}

This prospective observational study was conducted among 350 participants who attended the Bashundhara AdDin Medical College Hospital, Hasnabad, South Keranigonj, Dhaka, Bangladesh after confirmation by RTPCR. Using $5 \mathrm{ml}$ fasting venous blood samples different haematological and biochemical biomarkers were analyzed and these were analyzed in auto analysis using a standard protocol as per the manufacturer's instructions. According to the inclusion criteria of this study, only RT-PCR positive, non-duplicate sequential cases, patients with at least one sign or symptom of either fever, altered smell or taste, or acute respiratory disease, patients with the presence of clinical features that are unexplainable by any other disease and or suggested by computed mammography scan were included as the study subjects. Besides these, patients with a history of travel to another country in the previous 14 days before the onset of symptoms suggesting COVID-19 infection and positive RT-PCR case for SARS-CoV-2 or close contact with a patient confirmed positive by real-time PCR (RT-PCR) were included. On the other hand, according to the exclusion criteria of this study, all RT-PCR negative cases for SARS-CoV-2 and patients with bronchitis or pneumonia or acute and chronic eosinophilic pneumonia and COVID-19 positive case with congestive heart failure (CHF) were excluded. From upper respiratory specimens (nasopharyngeal swabs, oropharyngeal swabs) the real-time RT-PCR test is based on the qualitative detection of nucleic acid from the SARS-CoV-2. Swabs would have to be placed immediately after collection into a sterile tube containing 2-3 $\mathrm{mL}$ of either viral transport medium (VTM). Overnight fasting blood sample of $5 \mathrm{ml}$ was collected from each participant in a plain vial for serum testing, EDTA (k3EDTA) vial for estimation of hematological parameters citrated vial for D-dimer assessment. The estimation of coronavirus disease was done by RT-PCR with the help of Quant Studio ${ }^{\text {TM}} 5$ Real-Time PCR System (Ther mo fisher, USA) and the result was calculated on the basis of cycle threshold (CT) value and graphical analysis. The qualitative detection of SARS-CoV2 viral RNA was done in the human nasopharyngeal swab, oropharyngeal swab, anterior nasal swab, mid-turbinate, and sputum specimens from individuals who are "suspected of COVID-19" by the health care providers. The blood samples were studied in the hospital laboratory by the laboratory technician using the Medonic (BOULe) auto analyzer. The $\mathrm{CBC}$ results obtained from this analysis were studied and approved by a pathologist.

Severity Status Defining of COVIT-19:

The following features were considered as of non-critically [12] affected patients:

1. Fever, cough and other respiratory symptoms. 
2. $<50 \%$ of lung involvement on either chest X-ray or HRCT.

3. Lung imaging showed viral pneumonia.

4. No oxygen support is required.

5. Discharge after 10 days of symptom onset.

6. Blood oxygen saturation between $94 \%$ to $84 \%$.

7. $\mathrm{CRP}=5-10 \mathrm{mg} / \mathrm{L}, \mathrm{D}$-dimer $=450-1000 \mathrm{ng} / \mathrm{mL}$, serum ferritin=500-1000 ng/mL.

The following characteristics were considered as of critically affected patients:

1. $>50 \%$ of flung involvement on either chest X-ray or HRCT.

2. Blood oxygen saturation $<84 \%$.

3. Shock.

4. Acute Respiratory Distress Syndrome (ARDS).

5. Cardiac injury.

6. Multi-organ dysfunction.

The measurement principles of the Medonic (BOULe) based on impedance for cell counts and spectrophotometry for hemoglobin (HGB). Medonic has three main components to identify blood cell, Electrical impedance: Accurate identification of red blood cells and platelets. Laser-based flow cytometry: white blood cells identification. Colorimetric: determination of hemoglobin. Finally, results were analyzed using standard statistical calculation by $\%$ positivity, confidence interval, $p$ values where $p \leq 0.05$ was considered as statistically significant.

\section{Results}

Using a standard protocol as per the manufacturer's instructions, different haematological and biochemical biomarkers were analyzed using $5 \mathrm{ml}$ fasting venous blood samples and these were analyzed in auto analysis. In all COVID-19 positive cases, the average duration of symptoms before admission was 10 days. Among a total of 350 patients, $133(38 \%)$ were critically ill and 217 (62\%) were non-critical in condition based on the different clinical and diagnostic criteria. The average age of the total participants was $47.27 \pm$ 14.66 years. In the critical group, it was $54.19 \pm 15.23$ and in the non-critical group, it was $43.03 \pm 13.68$ years. So, the mean age of critical patients was higher than that of noncritical patients. In terms of severity, the maximum number of patients were belonging to age group 33 to 47 , which was $34.59 \%$ in critical $47.93 \%$ in non-critical, and $42.86 \%$ among total patients. Among total participant's male patients were $73 \%$ whereas female patients were $27 \%$. In the critical and non-critical groups, the ratios of male-female were similar to the total patients. In this study among participants, the most common risk factor was systemic hypertension which was found in $45.86 \%$ of critical, $47 \%$ of non-critical, and $46.57 \%$ of total patients. Besides these, the frequencies of diabetes mellitus were also noticeable. Among total participants, the most common complaints inpatient was fever in $51 \%$, altered taste, and smell in $50 \%$, headache in $25 \%$, and shortness of breath in $27 \%$ of patients. In analyzing the haematological and biochemical parameters among participants we found 'extremely significant correlations' between critical and noncritical groups in $\mathrm{HBC}(\mathrm{gm} / \mathrm{dl}), \mathrm{TLC} / \mathrm{ml}, \mathrm{PCV}(\%)$, Platelet Counts $(\mathrm{U} / \mathrm{mcL}), \mathrm{S}$. Creatinine $(\mathrm{mg} / \mathrm{dl})$ and D-Dimer $(\mu \mathrm{g} / \mathrm{ml})$ test results where $p$ values were $<0.0001$. On the other hand, we found only 'significant correlation' between critical and non-critical groups in NLR (\%), CRP (mg/L) and LDH (U/L) test results where the $\mathrm{p}$ values were $<0.05$. In this study, in critical participant group, the mean $( \pm \mathrm{SD}) \mathrm{HBC}(\mathrm{gm} / \mathrm{dl})$, RBC (1012/L), TLC/ml, PCV (\%), NLR (\%), Platelet Counts $(\mathrm{U} / \mathrm{mcL}), \mathrm{SGOT} / \mathrm{L}$ and SGPT/L were found $11.56 \pm 2.07$, $3.64 \pm 2.82, \quad 12372 \pm 2920, \quad 29.17 \pm 7.84, \quad 2.8 \pm 0.32$, $98743 \pm 32127,67.91 \pm 31.54$ and $71.39 \pm 33.74$ respectively. On the other hand, in non-critical patient group those reading were found $12.78 \pm 2.17,4.02 \pm 2.90,10956 \pm 2744,35.03 \pm 8.22$, $2.7 \pm 0.28, \quad 129544 \pm 51228, \quad 65.68 \pm 27.96$ and $67.55 \pm 26.57$ respectively. Moreover, in critical patient group the mean $( \pm \mathrm{SD})$ ALP (IU/L), Serum Urea $(\mathrm{mg} / \mathrm{dl})$, S. Creatinine $(\mathrm{mg} / \mathrm{dl})$, CRP $(\mathrm{mg} / \mathrm{L})$, D-Dimer $(\mu \mathrm{g} / \mathrm{ml})$, Serum Ferritin $(\mu \mathrm{g} / \mathrm{mL})$ and $\mathrm{LDH}(\mathrm{U} / \mathrm{L})$ were $161.65 \pm 52.49,46.06 \pm 16.11$, $1.9 \pm 0.8, \quad 47.15 \pm 22.71, \quad 2.77 \pm 1.92, \quad 1118.05 \pm 265.81$ and $379.94 \pm 101.91$ respectively. On the other hand, in noncritical patient group those readings were found $168.16 \pm 55.36, \quad 43.68 \pm 17.94, \quad 1.5 \pm 0.9, \quad 39.35 \pm 23.22$, $2.04 \pm 1.33,739.86 \pm 142.93$ and $344.16 \pm 97.55$ respectively.

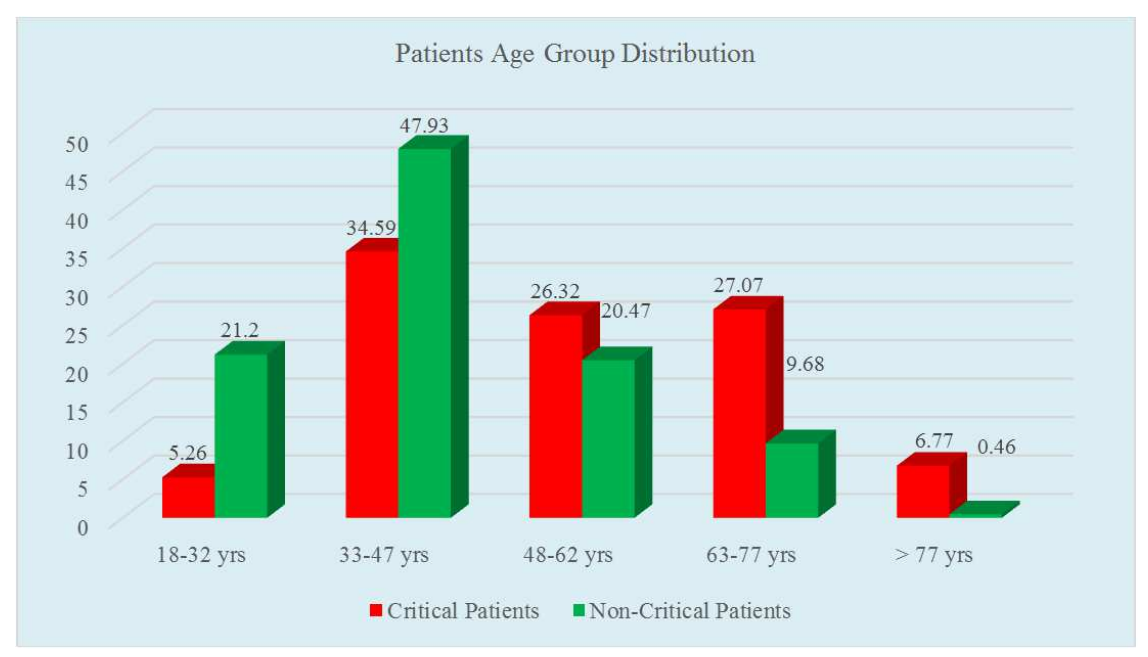

Figure 1. Patients Age Group Wise Distribution. 
Table 1. Age distribution of participants $(N=350)$.

\begin{tabular}{lllllll}
\hline \multirow{2}{*}{ Age (Year) } & Critical $(\mathbf{n}=\mathbf{1 3 3})$ & \multicolumn{2}{c}{ Non-critical $(\mathbf{n}=\mathbf{2 1 7})$} & \multicolumn{2}{l}{ Total $(\mathbf{N}=\mathbf{3 5 0})$} \\
\cline { 2 - 7 } & $\mathbf{n}$ & $\mathbf{\%}$ & $\mathbf{n}$ & $\mathbf{\%}$ & $\mathbf{n}$ & $\mathbf{\%}$ \\
\hline $18-32$ yrs. & 7 & 5.26 & 46 & 21.2 & 53 & 15.14 \\
$33-47$ yrs. & 46 & 34.59 & 104 & 47.93 & 150 & 42.86 \\
$48-62$ yrs. & 35 & 26.32 & 45 & 20.74 & 80 & 22.86 \\
$63-77$ yrs. & 36 & 27.07 & 21 & 9.68 & 57 & 16.29 \\
$>77$ yrs. & 9 & 6.77 & 1 & 0.46 & 10 & 2.86 \\
Mean \pm SD & $54.19 \pm 15.23$ & & $43.03 \pm 13.68$ & & $47.27 \pm 14.66$ \\
\hline
\end{tabular}

Table 2. Gender distribution of participants $(N=350)$.

\begin{tabular}{lllllll}
\hline \multirow{2}{*}{ Gender } & Critical $(\mathbf{n}=\mathbf{1 3 3})$ & \multicolumn{2}{c}{ Non-critical $(\mathbf{n}=\mathbf{2 1 7})$} & \multicolumn{2}{c}{ Total $(\mathbf{N}=\mathbf{3 5 0})$} \\
\cline { 2 - 7 } & $\mathbf{n}$ & $\mathbf{\%}$ & $\mathbf{n}$ & $\mathbf{\%}$ & $\mathbf{n}$ & $\mathbf{\%}$ \\
\hline Male & 99 & 74.44 & 156 & 71.89 & 255 & 72.86 \\
Female & 34 & 25.56 & 61 & 28.11 & 95 & 27.14 \\
\hline
\end{tabular}

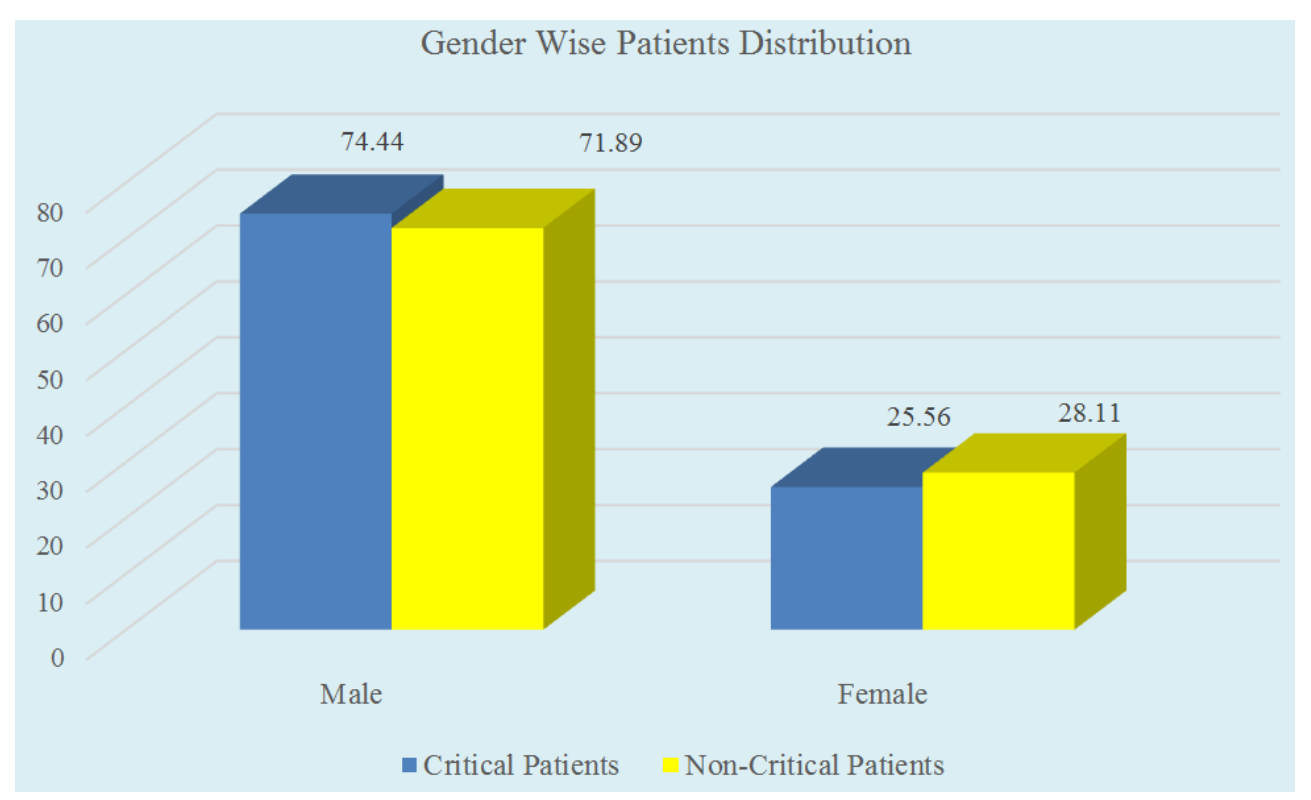

Figure 2. Patients Gender Wise Distribution.

Table 3. Risk factors and clinical features among participants $(N=350)$.

\begin{tabular}{|c|c|c|c|c|c|c|}
\hline \multirow{2}{*}{ Characteristics } & \multicolumn{2}{|c|}{ Critical (n=133) } & \multicolumn{2}{|c|}{ Non-critical $(n=217)$} & \multicolumn{2}{|c|}{ Total $(\mathrm{N}=350)$} \\
\hline & $\mathbf{n}$ & $\%$ & $\mathbf{n}$ & $\%$ & $\mathbf{n}$ & $\%$ \\
\hline \multicolumn{7}{|l|}{ Risk factor distribution } \\
\hline Systemic hypertension & 61 & 45.86 & 102 & 47.0 & 163 & 46.57 \\
\hline Other cardiovascular disease & 29 & 21.8 & 57 & 26.27 & 86 & 24.57 \\
\hline Diabetes mellitus & 66 & 49.62 & 81 & 37.33 & 147 & 42.0 \\
\hline \multicolumn{7}{|l|}{ Signs and symptoms distribution } \\
\hline Fever & 77 & 57.89 & 102 & 47.0 & 179 & 51.14 \\
\hline Fatigue & 34 & 25.56 & 19 & 8.76 & 53 & 15.14 \\
\hline Dry cough & 30 & 22.56 & 46 & 21.20 & 76 & 21.71 \\
\hline Shortness of breath & 42 & 31.58 & 52 & 23.96 & 94 & 26.86 \\
\hline Altered taste and smell & 77 & 57.89 & 98 & 45.16 & 175 & 50.0 \\
\hline Vomiting & 22 & 16.54 & 37 & 17.05 & 59 & 16.86 \\
\hline Headache & 19 & 14.29 & 67 & 30.88 & 86 & 24.57 \\
\hline Diarrhoea & 4 & 3.01 & 35 & 16.13 & 39 & 11.14 \\
\hline
\end{tabular}

Table 4. Haematological and biochemical parameters among participants $(N=350)$.

\begin{tabular}{|c|c|c|c|c|c|}
\hline \multirow{2}{*}{ Lab. parameters } & \multirow{2}{*}{ Critical $(n=133)$} & \multirow{2}{*}{ Non-critical $(n=217)$} & \multirow{2}{*}{ p- Value } & \multicolumn{2}{|l|}{$95 \%$ CI } \\
\hline & & & & Maximum & Minimum \\
\hline HBC (gm/dl) & $11.56 \pm 2.07$ & $12.78 \pm 2.17$ & $<0.0001$ & 1.66 & 0.16 \\
\hline $\operatorname{RBC}\left(10^{12} / \mathrm{L}\right)$ & $3.64 \pm 2.82$ & $4.02 \pm 2.90$ & 0.230 & 1.61 & 0.41 \\
\hline $\mathrm{TLC} / \mathrm{ml}$ & $12372 \pm 2920$ & $10956 \pm 2744$ & $<0.0001$ & 2134 & 812 \\
\hline PCV (\%) & $29.17 \pm 7.84$ & $35.03 \pm 8.22$ & $<0.0001$ & 2.9 & 1.44 \\
\hline
\end{tabular}




\begin{tabular}{|c|c|c|c|c|c|}
\hline \multirow{2}{*}{ Lab. parameters } & \multirow{2}{*}{ Critical $(n=133)$} & \multirow{2}{*}{ Non-critical $(n=217)$} & \multirow{2}{*}{ p- Value } & \multicolumn{2}{|l|}{$95 \%$ CI } \\
\hline & & & & Maximum & Minimum \\
\hline NLR (\%) & $2.8 \pm 0.32$ & $2.7 \pm 0.28$ & 0.002 & 0.76 & 0.13 \\
\hline Platelet Counts (U/mcL) & $98743 \pm 32127$ & $129544 \pm 51228$ & $<0.0001$ & 62345 & 11428 \\
\hline $\mathrm{SGOT} / \mathrm{L}$ & $67.91 \pm 31.54$ & $65.68 \pm 27.96$ & 0.491 & 19.17 & 4.38 \\
\hline SGPT/L & $71.39 \pm 33.74$ & $67.55 \pm 26.57$ & 0.238 & 21.36 & 4.88 \\
\hline ALP (IU/L) & $161.65 \pm 52.49$ & $168.16 \pm 55.36$ & 0.277 & 59.14 & 17.97 \\
\hline Serum Urea (mg/dl) & $46.06 \pm 16.11$ & $43.68 \pm 17.94$ & 0.212 & 8.21 & 4.95 \\
\hline S. Creatinine $(\mathrm{mg} / \mathrm{dl})$ & $1.9 \pm 0.8$ & $1.5 \pm 0.9$ & $<0.0001$ & 0.6 & 0.05 \\
\hline $\mathrm{CRP}(\mathrm{mg} / \mathrm{L})$ & $47.15 \pm 22.71$ & $39.35 \pm 23.22$ & 0.002 & 19.38 & 3.03 \\
\hline D-Dimer $(\mu \mathrm{g} / \mathrm{ml})$ & $2.77 \pm 1.92$ & $2.04 \pm 1.33$ & $<0.0001$ & 0.47 & 0.06 \\
\hline Serum Ferritin $(\mu \mathrm{g} / \mathrm{mL})$ & $1118.05 \pm 265.81$ & $739.86 \pm 142.93$ & $<0.0001$ & 65.55 & 15.83 \\
\hline $\mathrm{LDH}(\mathrm{U} / \mathrm{L})$ & $379.94 \pm 101.91$ & $344.16 \pm 97.55$ & 0.001 & 118.76 & 45.78 \\
\hline
\end{tabular}

Table 5. Final outcome among the participants $(N=350)$.

\begin{tabular}{lllllll}
\hline \multirow{2}{*}{ Clinical outcome } & \multicolumn{2}{c}{ Critical $(\mathbf{n}=\mathbf{1 3 3})$} & \multicolumn{2}{c}{ Non-critical $(\mathbf{n}=\mathbf{2 1 7})$} & \multicolumn{2}{c}{ Total $(\mathbf{N}=\mathbf{3 5 0})$} \\
\cline { 2 - 7 } & $\mathbf{n}$ & $\mathbf{\%}$ & $\mathbf{n}$ & $\mathbf{\%}$ & $\mathbf{n}$ & $\mathbf{\%}$ \\
\hline Death & 10 & 7.52 & 3 & 1.38 & 13 & 3.71 \\
Survived & 123 & 92.48 & 214 & 98.62 & 337 & 96.29 \\
Total & 133 & 100.0 & 217 & 100.0 & 350 & 100.0 \\
\hline
\end{tabular}

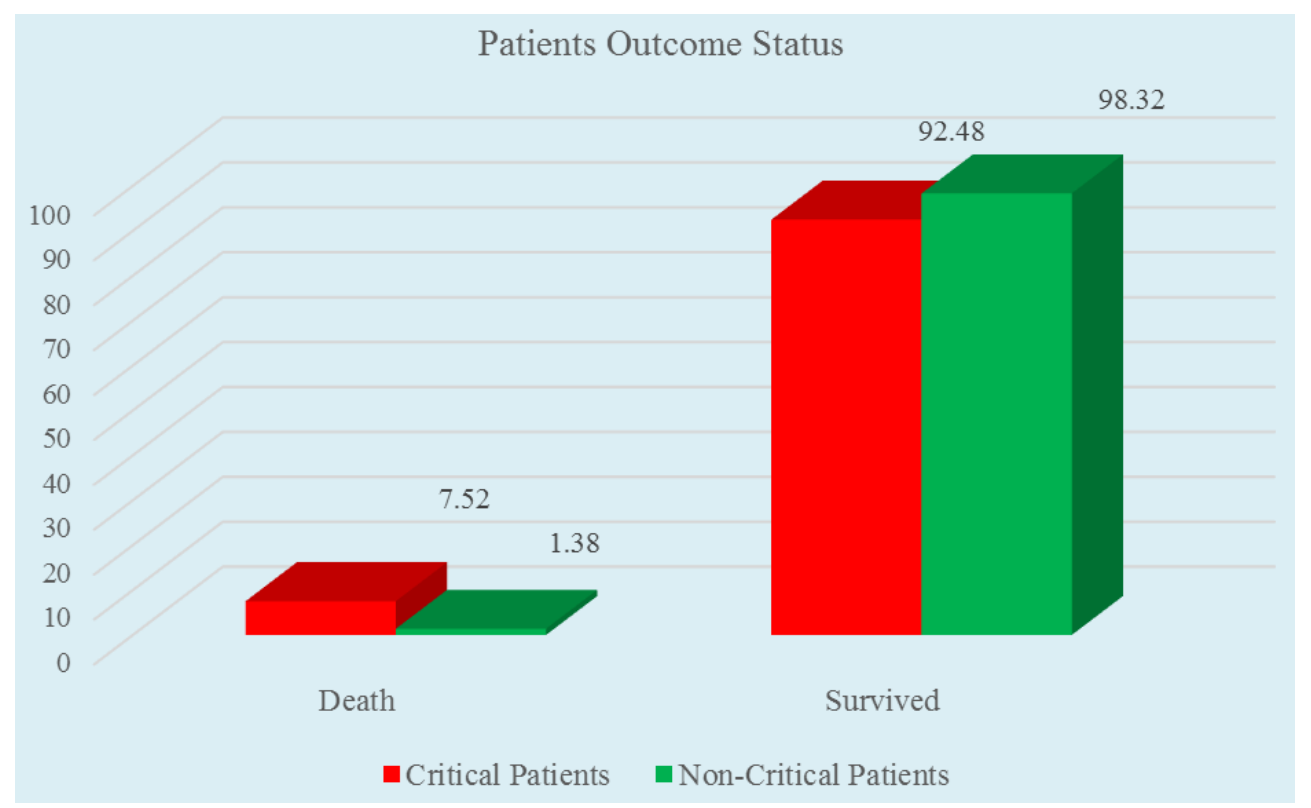

Figure 3. Patients Outcome Status.

\section{Discussion}

The aim of this study was to assess the COVID-19 status of Covid patients by haematological and biochemical markers. A heterogeneous and evolving approach for diagnosis of infection in patients to determine have taken in the emergence of the SARS-CoV-2 infection affected countries. As per our study, we analyzed several clinical, haematological as well as biochemical laboratory parameters. They play an important role in the early diagnosis and management of COVID-19 positive cases and proves their pivotal role by providing the clinical status of patients and a number of useful prognostic markers. To detect SARS-CoV2 RNA in a given specimen under the guidelines given by WHO in 2020, a commercial supplied RT-PCR kit and manual/automation methods of RNA extraction was applied which was similar to other studies by Palmas et al. [13] But for the detection of the similar virus, a study done by the Centre for disease control and prevention (CDC) 2020, used nasal mid-turbinate swab, saliva specimen and nasopharyngeal aspirate as a specimen. [14] In our study we included only RT-PCR positive cases as our study people. Out of all 350 confirmed cases of SARS-COV-2, the malefemale ratio was $2.7: 1$. The average age of the participants was $47.27 \pm 14.66$. The average age was found to be higher in critically as compared with the non-critically patients. This was supported by a similar study conducted by Guan et al., [15] and another study conduct by Li et al. [16] In this study among participants, the most common risk factor was systemic hypertension which was found in $45.86 \%$ of critical, $47 \%$ of non-critical and $46.57 \%$ of total patients. Besides these, the frequencies of diabetes mellitus were also noticeable. Among total participants, the most common 
complaints inpatient was fever in $51 \%$, altered taste and smell in $50 \%$, headache in $25 \%$ and shortness of breath in $27 \%$ of patients. The finding regarding these parameters was seen to be higher in critically ill as compare to the noncritically ill patients which were higher in study conduct by the Huang et al., [17] in which fever (98\%) followed by cough $(76 \%)$ and myalgia or fatigue (44\%). In a study which was conducted by Yang et al. [18] In this study, in critical participant group, the mean $( \pm \mathrm{SD}) \mathrm{HBC}(\mathrm{gm} / \mathrm{dl}), \mathrm{RBC}$ $(1012 / \mathrm{L})$, TLC/ml, PCV (\%), NLR (\%), Platelet Counts $(\mathrm{U} / \mathrm{mcL}), \mathrm{SGOT} / \mathrm{L}$ and SGPT/L were found $11.56 \pm 2.07$, $3.64 \pm 2.82, \quad 12372 \pm 2920, \quad 29.17 \pm 7.84, \quad 2.8 \pm 0.32$, $98743 \pm 32127,67.91 \pm 31.54$ and $71.39 \pm 33.74$ respectively. On the other hand, in non-critical patient group those reading were found $12.78 \pm 2.17,4.02 \pm 2.90,10956 \pm 2744,35.03 \pm 8.22$, $2.7 \pm 0.28, \quad 129544 \pm 51228, \quad 65.68 \pm 27.96$ and $67.55 \pm 26.57$ respectively. Moreover, in critical patient group the mean $( \pm \mathrm{SD})$ ALP (IU/L), Serum Urea $(\mathrm{mg} / \mathrm{dl})$, S. Creatinine $(\mathrm{mg} / \mathrm{dl})$, CRP $(\mathrm{mg} / \mathrm{L})$, D-Dimer $(\mu \mathrm{g} / \mathrm{ml})$, Serum Ferritin $(\mu \mathrm{g} / \mathrm{mL})$ and $\mathrm{LDH}(\mathrm{U} / \mathrm{L})$ were $161.65 \pm 52.49,46.06 \pm 16.11$, $1.9 \pm 0.8, \quad 47.15 \pm 22.71, \quad 2.77 \pm 1.92, \quad 1118.05 \pm 265.81$ and $379.94 \pm 101.91$ respectively. On the other hand, in noncritical patient group those readings were found $168.16 \pm 55.36, \quad 43.68 \pm 17.94, \quad 1.5 \pm 0.9, \quad 39.35 \pm 23.22$, $2.04 \pm 1.33,739.86 \pm 142.93$ and $344.16 \pm 97.55$ respectively. In most of the variables, these values were similar in a study conducted by Usul et al. [19] Author Huang et al. [20] and $\mathrm{Hu}$ et al. [21] suggested in his study conducted in China that, the mean of neutrophil counts and TLC were higher in critically ill COVID-19 cases and $87.5 \%$ of critical patients having neutrophilia, which is similar with our study. TLC and increased neutrophil were observed as independent predictors of an adverse clinical outcome in a study. [22] Our findings were found similar as in some other studies conducted by Terpos et al. [23] and Henry et al. [24] On the other hand, in critically and non-critically groups the COVID-19 positive adult patients associated with increased severity and high mortality, had a low level of platelet count which was similar in a study done by Henry et al. [24] The value of LDH was statistically significant in our study, several other studies also concluded that LDH is significantly increased in patients experiencing the severe course of the disease compared to those with non-critically ill, thereby demonstrating its role as the most potential biomarker in predicting COVID-19 severity. Studies conducted by Zheng et al. [25] and Velavan et al, [26] also observed in their study that LDH is an important biomarker for disease progression and severity. All the findings may be helpful in further similar studies.

\section{Conclusion and Recommendation}

Haematological and biochemical markers may be considered as the most potential parameters in assessing the severity of COVID-19 infection. Available data suggest that several hematological and biochemical parameters might be responsible for the change in the duration ofSARS-CoV-2 infection and some of them can be considered significant predictors of unfavorable clinical outcomes and also help in reflecting changes in systemic inflammation of the renal, hepatic, cardiac, immune, hemostatic, bone marrow and peripheral blood systems. Advance training required for laboratory personnel who are responsible for collecting, transporting, and handling biological samples and carrying out the various laboratory tests for patients with COVID-19 is recommended.

\section{References}

[1] Perlman S. Another decade, another corona virus. N Engl J Med 2020; 382: 760-762.

[2] De Wit E, van Doremalen N, Falzarano D, Munster VJ. SARS and MERS: recent insights into emerging corona viruses. Nat Rev Microbiol. 2016; 14: 523.

[3] Jiang S, Xia S, Ying T, Lu L. A novel corona virus (2019$\mathrm{nCoV}$ ) causing pneumonia-associated respiratory 554.

[4] Phan LT, Nguyen TV, Luong QC, Nguyen TV, Nguyen HT, Le HQ et al. Importation and Human-to-Human Transmission of a Novel Corona virus in Vietnam. N Engl J Med. 2020; 382 (9): 872-874.

[5] Bloomgarden ZT. Diabetes and COVID-19. J Diabetes. 2020; 12 (4): $347-348$.

[6] Zhou F, Yu T, Du R et al. Clinical course and risk factors form ortality of adult in patients with COVID-19 in Wuhan, China: are trospective cohort study. Lancet. 2020; 395 (10229): $1054-1062$.

[7] Chen N, Zhou M, Dong X, QuJetal. Epidemiological and clinical characteristics of 99 cases of 2019 novel corona virus pneumonia in Wuhan, China: a descriptive study. Lancet. 2020; 395 (10223): 507-513.

[8] Singhal T. Are view of corona virus disease-2019 (COVID19). Indian J. Pediatr. 2020; 87 (4): 281-286.

[9] Brazil, Accuracy of diagnostic tests registered for COVID-19 Ministry of Health, Brasília; 2020.

[10] Bekdas M, Goksugur SB, Sarac EG, et al. Neutrophil/lymphocyte and Creactive protein/mean platelet volume ratios in differentiating between viral and bacterial pneumonias and diagnosing early complications in children. Saudi Med. J. 2014; 35 (5): 442-447.

[11] Mehta P, Mc Auley DF, Brown M, et al. COVID-19: consider cytokines tormsynd romesandim munos up pression. Lancet. 2020; 395: 1033-1034.

[12] Gul N, Usman U, Ahmed U, et al. Clinical characteristics and outcomes of COVID-19 pneumonia patients from an intensive care unit in Faisalabad, Pakistan. Authorea; 2020.

[13] Palmas G, Moriondo M, Trapani S, et al. Nasal swab as preferred clinical specimenforCOVID-19 testing in children. Pediatr Infect Dis J. 2020; 39 (9): e267-e270.

[14] Interim Guidelines for Collecting, Handling, and Testing Clinical Specimens for COVID-19. Updated; 2020. Available: https://www.cdc.gov/coronavirus/2019-ncov/lab /guidelinesclinical-specimen.html. 
[15] Guan WJ, NiZ Y, Hu Y, et al. Clinical characteristics of corona virus disease 2019 in China. N. Engl. J. Med. 2020; 382 (18): $1708-1720$

[16] LiQ, Guan X, Wu P, etal. Early transmission dynamics in Wuhan, China, of novel corona virus-infected pneumonia. N. Engl. J. Med. 2020; 382: 1199-1207.

[17] Huang C, Wang Y, LiX etal. Clinical features of patients infected with 2019 novel corona virus in Wuhan, China. Lancet. 2020; 395 (10223): 497-506.

[18] Yang X, Yu Y, Xu J, et al. Clinical course and outcomes of critically ill patients withSARS-CoV-2 pneumonia in Wuhan, China: as ingle-centered, retrospective, observational study. Lancet Respir Med. 2020; 8 (5): 475-481.

[19] Usul E, San I. The role of hematological parameters in COVID-19 patients in the emergency room. Biomark. Med 10.2217/bmm-2020-0317.

[20] Huang J, Cheng A, Lin S, etal. Individualized prediction no mograms for disease progression in mild COVID-19. J Med Virol. 2020; 10: 1002/jmv.25969.
[21] $\mathrm{Hu} \mathrm{L}$, Chen S, Fu Y, et al. Risk Factors Associated with Clinical Outcomes in 323 COVID-19 Hospitalized Patients in Wuhan, China. Clin in fect Dis. 2020; ciaa 539.

[22] Tsui PT, Kwok ML, Yuen H Et al. Severe acute respiratory syndrome: clinical out come and prognostic correlates. Emerging infectious diseases. 2003; 9 (9): 1064-1069.

[23] Terpos E, Ntanasis-Stathopoulos I, Elalamy I, et al. Hematological findings and complications of COVID-19. Am J Hematol. 2020; 95 (7): 834-847.

[24] Henry BM, de Oliveira MHS, Benoit S, et al. Hematologic, biochemical and immune biomarker abnormalities associated with severe illness and mortality in corona virus disease 2019 (COVID-19): a metaanalysis. Clin Chem Lab Med. 2020; 58 (7): 1021-1028.

[25] Zheng F, Tang W, Li H, Huang YX, Xie YL, Zhou ZG. Clinical characteristics of 161 cases of coronavirus disease 2019 (COVID-19) in Changsha. Eur Rev Med Pharmacol Sci. 2020; 24: 3404-3410.

[26] Velavan TP, Meyer CG. Mild versus severe COVID-19: Laboratory markers. Int JIn fec Dis. 2020; 95: 304-307. 